\title{
Knockdown of ZEB1 suppressed the formation of vasculogenic mimicry and epithelial-mesenchymal transition in the human breast cancer cell line MDA-MB-231
}

\author{
WEILI LIANG ${ }^{1}$, SHASHA SONG ${ }^{2}$, YINTAO XU ${ }^{3}$, HUIYING LI $^{4}$ and HUANTAO LIU ${ }^{1}$ \\ ${ }^{1}$ Department of Breast Surgery, Qilu Hospital of Shandong University, Jinan, \\ Shandong 250012; ${ }^{2}$ Department of Pathology, Jinan Central Hospital, Jinan, Shandong 250013; \\ ${ }^{3}$ Department of Gynecology and Obstetrics, Qilu Hospital of Shandong University, Jinan, Shandong 250012; \\ ${ }^{4}$ Department of Anesthesiology, The Second Hospital of Shandong University, Jinan, Shandong 250033, P.R. China
}

Received October 12, 2016; Accepted February 27, 2018

DOI: $10.3892 / \mathrm{mmr} .2018 .8677$

\begin{abstract}
Breast cancer is a common malignant tumor in women. It has been suggested that a type of microcirculation pattern that does not rely on host microvascular endothelial cells known as vasculogenic mimicry (VM) may contribute to the poor effect of anti-angiogenesis treatment on some patients with breast cancer. However, the formation and regulatory mechanism of VM in breast cancer are unclear and still require further investigation. The present study examined whether decreasing the expression of zinc finger E-box binding homeobox (ZEB1) using siRNA can inhibit the formation of VM in Triple Negative Breast Cancer (TNBC), and its specific function and molecular mechanism. mRNA and protein expression were detected by RT-qPCR and western blotting. Invasion assay and tube formation assay were also performed. The results demonstrated that ZEB1 small hairpin (sh)RNA inhibited the formation of VM. Knockdown of ZEB1 markedly inhibited the expression of vimentin in MDA-MB-231 cells and markedly increased the expression of E-cadherin. It was suggested that ZEB1 shRNA may have inhibited the epithelial-mesenchymal transition (EMT). In addition, ZEB1 shRNA inhibited the invasion of MDA-MB-231 cells and suppressed the expression of fetal liver kinase 1 (flk-1). The flk-1 inhibitor Semaxanib inhibited the formation of VM; thus, ZEB1 shRNA inhibited EMT and cell invasion, and may have inhibited the formation of VM through flk-1. The present study contributed further understanding on the theory of tumor
\end{abstract}

Correspondence to: Dr Huantao Liu, Department of Breast Surgery, Qilu Hospital of Shandong University, 107 Wenhua Xi Road, Jinan, Shandong 250012, P.R. China

E-mail:1r9413@163.com

Key words: breast cancer, vasculogenic mimicry, zinc finger E-box binding homeobox 1, epithelial-mesenchymal transition, fetal liver kinase 1 angiogenesis and provided theoretical basis for novel targeted therapy of TNBC.

\section{Introduction}

Breast cancer is a common malignant tumor in women and its incidence increases every year; it has therefore become a serious threat to women's health $(1,2)$. In recent years, there has been marked progress in the diagnosis and treatment of breast cancer; however, patient mortality has not been significantly improved (3,4). Currently, Triple Negative Breast Cancer (TNBC) with all negative estrogen receptor/progesterone receptor/human epidermal growth factor receptor- 2 has become a growing concern for clinicians (5). TNBCs account for $\sim 15-26 \%$ of breast cancer cases $(5,6)$. Due to its phenotype and characteristics, TNBC is a more aggressive type of cancer and is easy to metastasize, which reduces the number of effective target sites for treatment $(7,8)$. The survival rate of TNBC is markedly lower than that of other types of breast cancer $(9,10)$. As such, TNBC has become a key area of research in recent years.

In the clinic, previous studies have revealed that the effect of anti-angiogenesis treatment in some patients was quite poor and was much less successful than it was expected to be (11-13). As a result, it has been suggested that there may be a novel mode of circulation in tumor blood supply. Vasculogenic mimicry (VM) was first observed in high invasive uveal melanoma (14). Following further research, VM has been confirmed in invasive breast cancer (15), ovarian cancer (16), glioma (17), liver cancer and gastrointestinal stromal tumors (18). VM is closely associated with tumor growth, invasion, metastasis and prognosis of patients. Patients with VM often have shorter survival periods and a poorer prognosis (19-21). VM enables tumor cells to simulate endothelial cell function by reconstruction and forming a unique circulation conduit structure (20). Due to VM, traditional anti-angiogenesis treatment cannot completely block the blood supply to tumors $(19,21)$. However, its formation and regulatory mechanism are still unclear and require further research in TNBCs.

Epithelial-mesenchymal transition (EMT) provides a novel reasoning to explain the mechanism of VM formation 
in epithelial tumors. EMT causes epithelial cells to lose their differentiated phenotype and specific epithelial cell features including cell adhesion, top-basal polarity and poor athletic ability; however, epithelial cells also obtain some mesenchymal cell phenotypes such as an enhanced moving metastasis ability and a strong anti-apoptosis ability (22). When epithelial cells undergo EMT, epithelial cell markers including E-cadherin, desmoplakin, tight junction protein and cytokeratin are downregulated, and mesenchymal cell markers including vimentin, fibronectin, $\mathrm{N}$-Cadherin and $\alpha$-smooth muscle actin are upregulated (23). The formation of VM is very similar to the EMT process. In colon cancer samples with VM, it was observed that Zinc finger E-box binding homeobox (ZEB1) and vimentin expression were upregulated, and E-cadherin expression was downregulated. Following ZEB1 knockdown, the formation of VM was inhibited and the cell phenotype was recovered (24), indicating that the EMT process may be regulated by ZEB1 and that it may serve an important role in VM formation. Therefore, the transcription factor ZEB1 may also be closely associated with VM formation in breast cancer via the regulation of EMT. Furthermore, vascular endothelial growth factor (VEGF) serves an important role in the growth of tumor blood vessels. Fetal liver kinase 1 [flk-1; also known as VEGF receptor 2 (VEGFR-2)] is an important VEGF receptor that is primarily expressed in endothelial cells (25).

The aim of the present study was to examine whether decreasing the expression of ZEB1 in turn inhibited VM, via flk-1, and the EMT process in TNBC.

\section{Materials and methods}

Cell culture. The human breast cancer cell line MDA-MB-231 (American Type Culture Collection, Manassas, VA, USA) was cultured in RPMI-1640 medium (Invitrogen; Thermo Fisher Scientific, Inc., Waltham, MA, USA) with $10 \%$ fetal bovine serum (Gibco; Thermo Fisher Scientific, Inc.), 4 mM L-glutamine and $1 \%$ penicillin-streptomycin (Beyotime Institute of Biotechnology, Haimen, China) at $37^{\circ} \mathrm{C}$ in $5 \% \mathrm{CO}_{2}$. Cells $\left(5 \times 10^{5}\right)$ were seeded into 6 -well plates. At $80 \%$ confluence, $1 \mu \mathrm{M}$ Semaxanib (Sigma-Aldrich; Merck $\mathrm{KGaA}$, Darmstadt, Germany) was added to the cells for $1 \mathrm{~h}$ preincubation to inhibit flk-1. Following the addition of $1 \mathrm{ml}$ cell suspension to cell culture plates and culture for $72 \mathrm{~h}$, the ability of cells to form a canal structure (tube) was periodically observed under an inverted microscope (Olympus IX70; Olympus Corporation, Tokyo, Japan).

ZEB1 gene silencing. The non-effective scrambled-small hairpin (sh)RNA plasmid (cat. no. TR30021) and ZEB1 shRNA plasmid (cat. no. TL301174) were purchased from OriGene Technologies, Inc. (Rockville, MD, USA). These plasmids $(50 \mu \mathrm{M})$ were transfected into cells to produce negative control (vector, NC) and ZEB1-silenced MDA-MB-231 cells using the FuGENE ${ }^{\circledR}$ HD transfection reagent (Promega Corporation, Madison, WI, USA) according to the manufacturer's protocols. For ZEB1 knockdown, four shRNA constructs (cat. no. TL301174; OriGene Technologies, Inc. mixed shRNAs $(15 \mu \mathrm{M}$ of each to obtain $60 \mu \mathrm{M})$ were combined and then transfected. Following Geneticin selection, the downregulation of ZEB1 was confirmed by reverse transcription-quantitative polymerase chain reaction (RT-qPCR) and western blot analysis.

$R T-q P C R$. Total RNA was isolated from cells using TRIzol (Invitrogen; Thermo Fisher Scientific, Inc., Waltham, MA, USA) and the concentration was determined using the GeneQuant II (Pharmacia Biotech; GE Healthcare, Uppsala, Sweden) at $260 \mathrm{~nm}$. The RT reaction and cDNA synthesis were performed according to the manufacturer's protocols (Superscript One-step RT-PCR System; Invitrogen; Thermo Fisher Scientific, Inc.).qPCR analysis was performed on the ABI 7500 system (Applied Biosystems; Thermo Fisher Scientific, Inc.) using the SYBR Premix Ex Taq GC kit (Takara Bio, Inc., Otsu, Japan) at $95^{\circ} \mathrm{C}$ for $2 \mathrm{~min}, 94^{\circ} \mathrm{C}$ for $20 \mathrm{sec}, 58^{\circ} \mathrm{C}$ for $20 \mathrm{sec}$ and $72^{\circ} \mathrm{C}$ for $20 \mathrm{sec}$ (40 cycles). The stem-loop primers used for PCR amplification were synthesized by Guangzhou RiboBio Co., Ltd. (Guangzhou, China). All primer sequences used for analysis were as follow: ZEB1 forward, 5'-CAGGCAGAT GAAGCAGGATG-3' and reverse 5'-CAGCAGTGTCTTGTT GTTGTAG-3'; GAPDH forward, 5'-ACACCCACTCCTCCA CCTTT and reverse 5'-TTACTCCTTGGAGGCCATGT. The relative levels of ZEB1 mRNA were normalized to those of GAPDH using the relative $2^{-\Delta \Delta \mathrm{Cq}}$ method (26).

Western blot analysis. Protein in cell lysate was extracted using RIPA (Beyotime Institute of Biotechnology) and then the concentration was determined by the BCA method (Beyotime Institute of Biotechnology); it was stored at $-80^{\circ} \mathrm{C}$ until required. A total of $60 \mu \mathrm{g}$ protein in each sample was separated by $8 \%$ SDS-PAGE and transferred to a nitrocellulose membrane. The nitrocellulose membrane was then blocked in TBST containing $0.1 \%$ Tween-20 and 5\% fat-free dry milk for $2 \mathrm{~h}$ at $4^{\circ} \mathrm{C}$, followed by incubation with the primary antibodies, anti-vimentin (sc-6260; 1:100; Santa Cruz Biotechnology, Inc., Dallas, TX, USA) and anti-E-cadherin (sc-21791; 1:100; Santa Cruz Biotechnology, Inc.) at $4^{\circ} \mathrm{C}$ overnight. The membrane was washed 3 times with TBST prior to HRP-conjugated secondary antibody (A0216; 1:1,000; Beyotime Institute of Biotechnology) incubation at room temperature for $2 \mathrm{~h}$, followed by a further 3 washes with TBST. Protein detection was performed using an enhanced chemiluminescence reagent kit (Beyotime Institute of Biotechnology). GAPDH (AF1186; Institute of Biotechnology) was used as the internal reference. Quantification was performed using ImageJ version 4.0 (National Institutes of Health, Bethesda, MD, USA).

Invasion assay. Invasion assays were performed as described previously (23). Under aseptic condition, Matrigel was diluted to $1 \mathrm{mg} / \mathrm{ml}$ with RPMI-1640 medium and $100 \mu \mathrm{l} /$ well Matrigel was added into 24-well cell culture plates for incubation at $37^{\circ} \mathrm{C}$ for $30 \mathrm{~min}$. Then, cells were trypsinized $(0.25 \%)$ and adjusted to $2.5 \times 10^{5} / \mathrm{ml}$. Matrigel was used to coat the Transwell cabin polycarbonate membrane for $1 \mathrm{~h}$ at $37^{\circ} \mathrm{C}$. Then, $60 \mu \mathrm{l} /$ well of the chemotactic factor, epidermal growth factor (10 ng/ml, Invitrogen; Thermo Fisher Scientific, Inc.) was added to the lower Transwell chamber. Cells in serum-free culture medium (Gibco; Thermo Fisher Scientific, Inc.) with $4 \mathrm{mM}$ L-glutamine and $1 \%$ penicillin-streptomycin were used to produce a single cell suspension at $1 \times 10^{5} /$ well cells. A total of $200 \mu \mathrm{l}$ cell suspension was added to the wells of the 
A

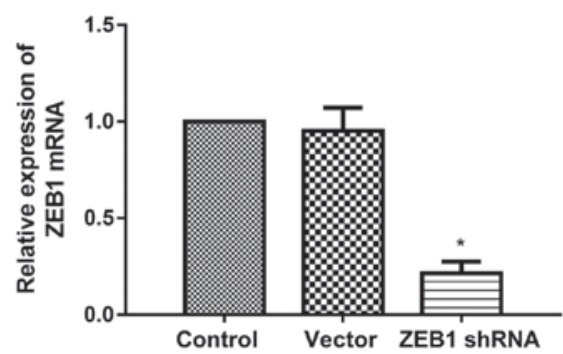

B

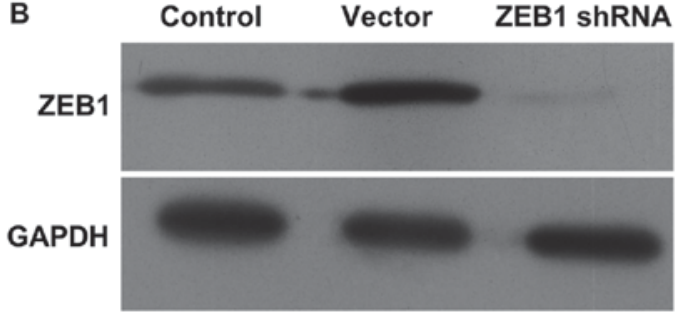

Figure 1. Inhibition of ZEB1 shRNA and the expression of ZEB1 at the transcriptional and translational levels. (A) Reverse transcription-quantitative polymerase chain reaction was performed to detect the mRNA levels of ZEB1. (B) Western blotting was performed detect the protein levels of ZEB1. Data are presented as the mean \pm standard deviation of 3 independent experiments. " $\mathrm{P}<0.05$ vs. control. ZEB1, zinc finger E-box binding homeobox; shRNA, small hairpin RNA.

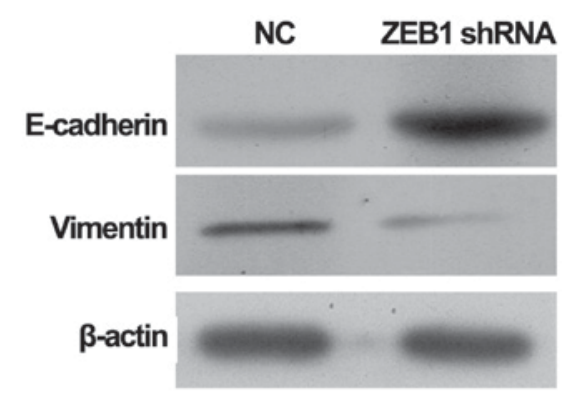

Figure 3. ZEB1 shRNA inhibited the epithelial-mesenchymal transition of MDA-MB-231 cells. The protein expression levels of E-cadherin and vimentin as determined by western blot analysis. ZEB1, zinc finger E-box binding homeobox; shRNA, small hairpin RNA; NC, negative control.

upper chamber for incubation at $37^{\circ} \mathrm{C}$ for $24 \mathrm{~h}$. Cells that had not migrated through the membrane were wiped away using wet cotton swabs. Following hematoxylin staining at room temperature for $30 \mathrm{~min}$ and washing with PBS, the number of cells that had migrated through the membrane were observed and counted using an Olympus IX70 inverted microscope (Olympus Corporation, Tokyo, Japan).

Statistical analysis. Data are presented as the mean \pm standard deviation of 3 independent experiments. SPSS version 13.0 software (SPSS, Inc., Chicago, IL, USA) was used to evaluate the data. Analysis of variance with a Bonferroni post hoc test were performed for multiple comparisons. $\mathrm{P}<0.05$ was considered to indicate a statistically significant difference.

\section{Results}

ZEB1 shRNA inhibits the expression of ZEB1 at the transcriptional and translational levels. In order to

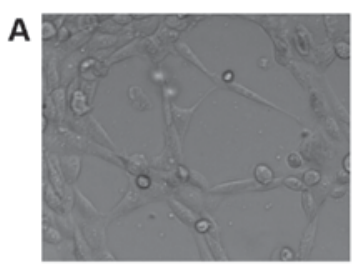

NC

B

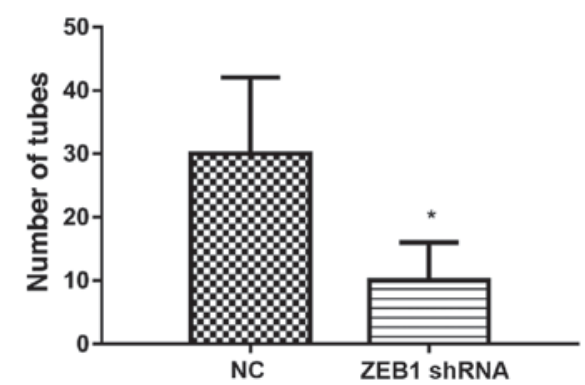

Figure 2. ZEB1 shRNA inhibited the formation of VM and the number of tubes. (A) VM formation was observed under a microscope (magnification, $\mathrm{x} 400)$ and the (B) number of tubes were counted. Data are presented as the mean \pm standard deviation of 3 independent experiments. ${ }^{*} \mathrm{P}<0.05$ vs. NC. ZEB1, zinc finger E-box binding homeobox; shRNA, small hairpin RNA; $\mathrm{NC}$, negative control.

silence ZEB1 in MDA-MB-231 cells, 4 constructs of ZEB1 shRNA were mixed and transfected into cells. The expression of ZEB1 at the mRNA and protein levels was then detected by RT-qPCR and western blotting, respectively (Fig. 1). As shown in Fig. 1A, the levels of ZEB1 mRNA in shRNA-transfected cells was significantly downregulated to $22 \%$ of the level presented by the control; however, the expression of ZEB1 mRNA was not significantly altered in the vector group. Similarly, the expression of ZEB1 protein was markedly downregulated by ZEB1 shRNA, though not by the vector (Fig. 1B). Thus, the expression of ZEB1 at the transcriptional and translational levels was downregulated by ZEB1 shRNA. These stably transfected cells were used for the following experiments.

ZEB1 shRNA inhibits the formation of VM. To detect the role of ZEB1 in the formation of VM, the cells that were stably transfected with ZEB1 shRNA were cultured on Matrigel pre-coated cell culture plates. Following $72 \mathrm{~h}$, the cells transfected with vector presented marked formation of VM (Fig. 2A). However, the formation of VM was markedly inhibited in ZEB1 shRNA transfected cells (Fig. 2A). For quantification, the number of tubes observed was calculated. As shown in Fig. 2B, the number of tubes was significantly reduced in the ZEB1 shRNA-transfected MDA-MB-231 cells (Fig. 2B). Thus, the results indicated that ZEB1 shRNA inhibited the formation of VM.

ZEB1 shRNA inhibits the EMT of MDA-MB-231 cells. To investigate the differences in EMT in ZEB1 shRNA-transfected MDA-MB-231 cells, the present study further detected the protein expression of E-cadherin and vimentin (Fig. 3). The results revealed that knockdown of ZEB1 using ZEB1 shRNA markedly inhibited the expression of vimentin in MDA-MB-231 cells when compared with NC 


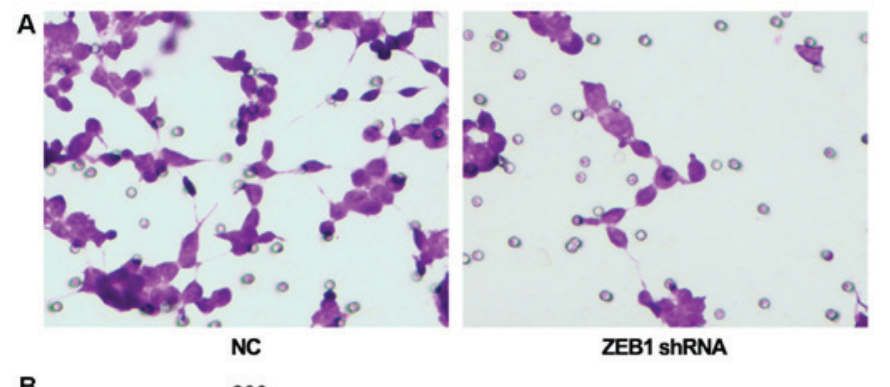

B

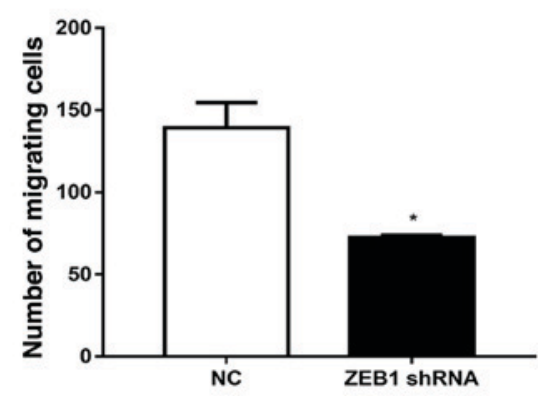

Figure 4. ZEB1 shRNA inhibited the cell invasion abilities of MDA-MB-231 cells. (A) An invasion assay (magnification, $\mathrm{x} 400$ ) was performed in order to (B) quantify the number of migrating cells. Data are presented as the mean \pm standard deviation of 3 independent experiments. "P<0.05 vs. NC. ZEB1, zinc finger E-box binding homeobox; shRNA, small hairpin RNA; $\mathrm{NC}$, negative control.

cells. By contrast, the protein expression of E-cadherin in ZEB1 shRNA-transfected MDA-MB-231 cells was markedly increased when compared with NC cells. The upregulation of E-cadherin and downregulation of vimentin suggested that ZEB1 shRNA may inhibit the EMT of MDA-MB-231 cells.

ZEB1 shRNA inhibits the invasion of MDA-MB-231 cells. The role of ZEB1 shRNA in the metastasis of MDA-MB-231 cells was also investigated via a Transwell assay (Fig. 4). In cells transfected with vector, $142 \pm 12$ cells migrated. However, in cells transfected with ZEB1 shRNA, the number of migrated cells was significantly reduced to $75 \pm 3$ cells (Fig. 4). This result further confirmed the potential role of ZEB1 in EMT, and also demonstrated that knockdown of ZEB1 significantly inhibited the invasion of MDA-MB-231 cells, indicating an important role of ZEB1 in metastasis.

ZEB1 shRNA inhibits the formation of VM via the downregulation of $f l k-1$. The expression of flk-1 in ZEB1 shRNA transfected MDA-MB-231 cells and its role in the formation of VM were further investigated (Fig. 5). The results of western blot analysis revealed that ZEB1 shRNA markedly inhibited the protein expression of flk-1 when compared with the cells transfected with vector (Fig. 5A). To further inhibit flk-1 expression, MDA-MB-231 cells were preincubated with $1 \mu \mathrm{M}$ Semaxanib for $1 \mathrm{~h}(27)$. Then, the formation of VM was observed and the results indicated that there was a marked reduction in VM formation in cells treated with Semaxanib (Fig. 5B). As shown in Fig. 5C, the number of tubes formed was significantly inhibited by Semaxanib pretreatment. Thus, inhibition of flk-1 protein in MDA-MB-231 cells inhibited the formation of VM. Taken together, these results suggested that ZEB1 shRNA may have inhibited the formation of VM via the downregulation of flk-1.
A
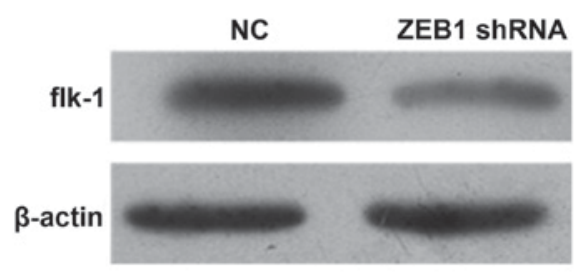

B

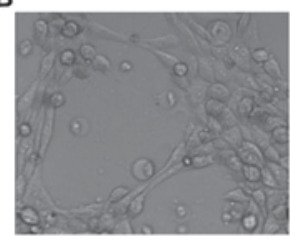

CT

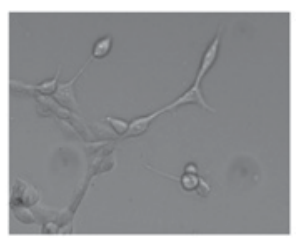

Semaxanib
C

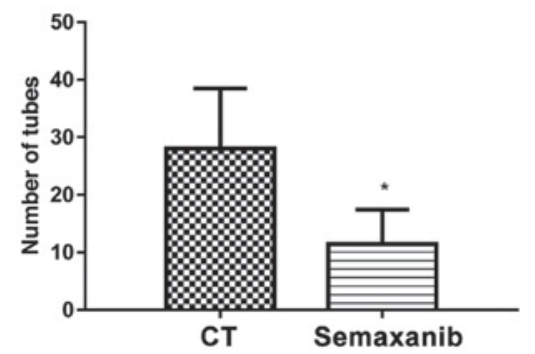

Figure 5. ZEB1 shRNA inhibited VM formation via flk-1 expression. (A) ZEB1 shRNA suppressed the protein expression of flk-1, as determined by western blot analysis. The flk-1 inhibitor Semaxanib (B) further inhibited VM formation (magnification, $\mathrm{x} 400$ ) and $(\mathrm{C})$ reduced the number of tubes observed. "P<0.05 vs. CT. ZEB1, zinc finger E-box binding homeobox; shRNA, small hairpin RNA; NC, negative control; CT, control.

\section{Discussion}

The present study determined whether decreasing the expression of ZEB1 can inhibit the formation of VM in TNBC, and also evaluated its specific function and molecular mechanism. The results demonstrated that ZEB1 shRNA inhibited the formation of VM, the expression of vimentin and flk-1, and cell invasion abilities; however, it promoted the expression of E-cadherin. In addition, the flk-1 inhibitor Semaxanib suppressed the formation of VM. Thus, knockdown of ZEB1 inhibited the EMT and may have suppressed the formation of VM in the human breast cancer cell line via the downregulation of flk-1. Therefore, ZEB1 may serve important roles in metastasis and the formation of VM in human breast cancer.

Whether VM lumen structure can be formed in three-dimensional culture is often used to identify whether tumor cells can form VM in vitro. Three-dimensional culture based on Matrigel is a type of in vitro cell culture technique (28). During the early stages of research, studies on the molecular mechanism of VM formation primarily focused on tumors arising from mesenchymal tissue (29). In recent years, VM has also been identified in tumors arising from the epithelium, including breast and ovarian cancers; however, there are few studies reporting the molecular mechanism of VM in epithelial tumor (30). Low differential MDA-MB-231 cells can form a typical lumen structure in vitro (29). The results of the present study further confirmed that the epithelial tumor cells MDA-MB-231 
could differentiate into the mesenchymal phenotype and form VM canal structure.

The EMT process is regulated by multiple signaling pathways and is involved in VM formation. Previous studies have demonstrated that the transcription factor $\mathrm{ZEB1}$ regulated EMT under physiological or pathological conditions $(31,32)$. ZEB1 is located in the short arm of chromosome 10, and is composed of two Zinc finger structure clusters and a homologous structure domain. In addition, ZEB1 regulates the expression of E-cadherin and vimentin at the transcriptional level, and enhances the metastasis ability of cells $(22,23)$. In colon cancer samples with VM, Liu et al (24) revealed that ZEB1 and vimentin expression was upregulated, and E-cadherin expression was downregulated. Removal of ZEB1 resulted in a reduction in VM and the recovery of the epithelial cell phenotype, which indicated that EMT regulated by ZEB1 may serve an important role in VM formation in colon cancer. The results of the present study demonstrated that ZEB1 shRNA also inhibited EMT and induced the recovery of the epithelial cell phenotype in the triple negative subtype of breast cancer. However, the association between EMT and the formation of VM requires further investigation.

Flk-1 (also known as VEGFR-2) is an important VEGF receptor that is primarily expressed in endothelial cells and which serves an important role in angiogenesis and contributes to the formation of VM (25). The results of the present study revealed that ZEB1 shRNA inhibited the expression of flk-1. To further investigate the role of flk-1 in the formation of VM, the flk-1 inhibitor Semaxanib was applied to cells. Inhibition of flk-1 significantly inhibited the formation of VM. Thus, knockdown of ZEB1 at least partially suppressed the formation of VM via the downregulation of flk-1.

In addition to EMT and the roles of $\mathrm{flk}-1$, the differentiation of tumor stem-like cells may be another important factor that should be further investigated. Cancer stem cells (CSC) are a small number of cells that possess self-renewal abilities. Bussolati et al (33) injected human breast CSCs into SCID mice and revealed that some vessels in the tumor were human-derived, indicating that the human breast CSCs were involved angiogenesis. CD133+ spongioblastoma stem-cell-like cells also had the potential for multi-directional differentiation, and were able to differentiate into tumor cells and endothelial cells (34-36). It is worth noting that previous studies have shown that ZEB1 can maintain self-renewal abilities and has the potential for rapid responses to differentiation cues from the action of the negative feedback loop with the microRNA200 family (37-39). This indicates that the transcription factor ZEB1 may participate in the regulation of EMT, and may also be associated with maintaining self-renewal and the potential for rapid responses to the differentiation cues of tumor cells.

Thus, the formation of VM and the role of ZEB1 are complex. The present study demonstrated that the knockdown of ZEB1 suppressed the formation of VM in the human breast cancer cell line MDA-MB-231 via the downregulation of flk-1, and it also inhibited the process of EMT. It was also revealed that ZEB1 may also promote VM formation in TNBC by promoting tumor cells to obtain some stem cell-like features; however, this requires further investigation. Although MDA-MB-231 cells are a well-established cell model for the TNBC, the group will consider other cell types in future studies. The results of the present study further clarify the mechanism of VM formation and provide theoretical basis for developing novel targets for TNBC therapy.

\section{Acknowledgements}

The authors thank all members of the Department of Breast Surgery, Qilu Hospital of Shandong University for their suggestions and critical reading of the manuscript.

\section{Funding}

The present study was supported by a grant from the Shandong Provincial Natural Science Foundation (Shandong, China; grant. no. ZR2015HM068). The funders had no role in study design, data collection and analysis, decision to publish, or preparation of the manuscript.

\section{Availability of data and materials}

The analyzed data sets generated during the study are available from the corresponding author on reasonable request.

\section{Authors' contributions}

HLiu: Conception and design of the experiments, editing the manuscript and organizing the team. WL, SS and YX: Performance of the experiments. HLi: Analysis of the data. WL: Wrote the paper.

\section{Ethics approval and consent to participate}

Not applicable.

\section{Consent for publication}

Not applicable.

\section{Competing interests}

The authors declare that they have no competing interests.

\section{References}

1. Cazzaniga ME, Cortesi L, Ferzi A, Scaltriti L, Cicchiello F, Ciccarese M, Torre SD, Villa F, Giordano M, Verusio C, et al: Metronomic chemotherapy in triple-negative metastatic breast cancer: The future is now? Int J Breast Cancer 2017: 1683060, 2017.

2. Chalakur-Ramireddy NKR and Pakala SB: Combined drug therapeutic strategies for the effective treatment of Triple Negative Breast Cancer. Biosci Rep 38: pii: BSR20171357, 2018.

3. Omarini C, Guaitoli G, Pipitone S, Moscetti L, Cortesi L, Cascinu $S$ and Piacentini F: Neoadjuvant treatments in triple-negative breast cancer patients: Where we are now and where we are going. Cancer Manag Res 10: 91-103, 2018.

4. Rabanal C, Ruiz R, Neciosup S and Gomez H: Metronomic chemotherapy for non-metastatic triple negative breast cancer: Selection is the key. World J Clin Oncol 8: 437-446, 2017.

5. Reaz S, Tamkus D and Andrechek ER: Using gene expression data to direct breast cancer therapy: evidence from a preclinical trial. J Mol Med (Berl) 96: 111-117, 2018. 
6. Sulaiman A and Wang L: Bridging the divide: Preclinical research discrepancies between triple-negative breast cancer cell lines and patient tumors. Oncotarget 8: 113269-113281, 2017.

7. Horton JK, Jagsi R, Woodward WA and Ho A: Breast cancer biology: Clinical implications for breast radiation therapy. Int $\mathrm{J}$ Radiat Oncol Biol Phys 100: 23-37, 2018.

8. Bartsch R and Bergen E: ASCO 2017: Highlights in breast cancer. Memo 10: 228-232, 2017.

9. Pal SK, Childs BH and Pegram M: Triple negative breast cancer: Unmet medical needs. Breast Cancer Res Treat 125: 627-636, 2011.

10. Yin WJ, Lu JS, Di GH, Lin YP, Zhou LH, Liu GY, Wu J, Shen KW, Han QX, Shen ZZ and Shao ZM: Clinicopathological features of the triple-negative tumors in Chinese breast cancer patients. Breast Cancer Res Treat 115: 325-333, 2009.

11. Paez-Ribes M, Allen E, Hudock J, Takeda T, Okuyama H, Viñals F, Inoue M, Bergers G, Hanahan D and Casanovas O: Antiangiogenic therapy elicits malignant progression of tumors to increased local invasion and distant metastasis. Cancer Cell 15: 220-231, 2009.

12. Ebos JM,Lee CR, Cruz-Munoz W, Bjarnason GA, Christensen JG and Kerbel RS: Accelerated metastasis after short-term treatment with a potent inhibitor of tumor angiogenesis. Cancer Cell 15 : 232-239, 2009

13. Carbone C, Moccia T, Zhu C, Paradiso G, Budillon A, Chiao PJ, Abbruzzese JL and Melisi D: Anti-VEGF treatment-resistant pancreatic cancers secrete proinflammatory factors that contribute to malignant progression by inducing an EMT cell phenotype. Clin Cancer Res 17: 5822-5832, 2011.

14. Maniotis AJ, Folberg R, Hess A, Seftor EA, Gardner LM, Pe'er J, Trent JM, Meltzer PS and Hendrix MJ: Vascular channel formation by human melanoma cells in vivo and in vitro: Vasculogenic mimicry. Am J Pathol 155: 739-752, 1999.

15. Shirakawa K, Wakasugi H, Heike Y, Watanabe I, Yamada S, Saito Kand KonishiF: Vasculogenic mimicry and pseudo-comedo formation in breast cancer. Int J Cancer 99: 821-828, 2002.

16. Wang JY, Sun T, Zhao XL, Zhang SW, Zhang DF, Gu Q, Wang XH, Zhao N, Qie S and Sun BC: Functional significance of VEGF-a in human ovarian carcinoma: Role in vasculogenic mimicry. Cancer Biol Ther 7: 758-766, 2008.

17. Liu XM, Zhang QP, Mu YG, Zhang XH, Sai K, Pang JC, Ng HK and Chen ZP: Clinical significance of vasculogenic mimicry in human gliomas. J Neurooncol 105: 173-179, 2011.

18. Sun B, Qie S, Zhang S, Sun T, Zhao X, Gao S, Ni C, Wang X, Liu Y and Zhang L: Role and mechanism of vasculogenic mimicry in gastrointestinal stromal tumors. Hum Pathol 39: 444-451, 2008

19. Sun T, Zhao N, Zhao XL, Gu Q, Zhang SW, Che N, Wang XH, Du J, Liu YX and Sun BC: Expression and functional significance of Twist1 in hepatocellular carcinoma: Its role in vasculogenic mimicry. Hepatology 51: 545-556, 2010

20. Li M, Gu Y, Zhang Z, Zhang S, Zhang D, Saleem AF, Zhao X and Sun B: Vasculogenic mimicry: A new prognostic sign of gastric adenocarcinoma. Pathol Oncol Res 16: 259-266, 2010

21. Gong W, Sun B, Zhao X, Zhang D, Sun J, Liu T, Gu Q, Dong X, Liu F, Wang Y, et al: Nodal signaling promotes vasculogenic mimicry formation in breast cancer via the Smad2/3 pathway. Oncotarget 7: 70152-70167, 2016.

22. Zeng YE, Yao XH, Yan ZP, Liu JX and Liu XH: Potential signaling pathway involved in sphingosine-1-phosphate-induced epithelial-mesenchymal transition in cancer. Oncol Lett 12 : 379-382, 2016

23. Zeng Y, Yao X, Chen L, Yan Z, Liu J, Zhang Y, Feng T, $\mathrm{Wu} J$ and Liu $X$ : Sphingosine-1-phosphate induced epithelial-mesenchymal transition of hepatocellular carcinoma via an MMP-7/syndecan-1/TGF- $\beta$ autocrine loop. Oncotarget 7: 63324-63337, 2016.
24. Liu Z, Sun B, Qi L, Li H, Gao J and Leng X: Zinc finger E-box binding homeobox 1 promotes vasculogenic mimicry in colorectal cancer through induction of epithelial-to-mesenchymal transition. Cancer Sci 103: 813-820, 2012.

25. Francescone R, Scully S, Bentley B, Yan W, Taylor SL, Oh D, Moral L and Shao R: Glioblastoma-derived tumor cells induce vasculogenic mimicry through Flk-1 protein activation. J Biol Chem 287: 24821-24831, 2012.

26. Livak KJ and Schmittgen TD: Analysis of relative gene expression data using real-time quantitative PCR and the 2(-Delta Delta C(T)) method. Methods 25: 402-408, 2001.

27. Li H, Song S, Xu Y, Zhao J and Liu H: Knockdown of ZEB1 suppresses the formation of vasculogenic mimicry in breast cancer cell line MDA-MB-231 through downregulation of Flk-1. Minerva Med 108: 191-193, 2017.

28. Wang H, Lin H, Pan J, Mo C, Zhang F, Huang B, Wang Z, Chen X, Zhuang J, Wang D and Qiu S: Vasculogenic mimicry in prostate cancer: The roles of EphA2 and PI3K. J Cancer 7: 1114-1124, 2016

29. Timoshenko AV, Kaltner H, Andrè S, Gabius HJ and Lala PK: Differential stimulation of VEGF-C production by adhesion/growth-regulatory galectins and plant lectins in human breast cancer cells. Anticancer Res 30: 4829-4833, 2010.

30. Yao L, Zhang D, Zhao X, Sun B, Liu Y, Gu Q, Zhang Y, Zhao X, Che N, Zheng Y, et al: Dickkopf-1-promoted vasculogenic mimicry in non-small cell lung cancer is associated with EMT and development of a cancer stem-like cell phenotype. J Cell Mol Med 20: 1673-1685, 2016

31. Li S, Zhang HY, Du ZX, Li C, An MX, Zong ZH, Liu BQ and Wang HQ: Induction of epithelial-mesenchymal transition (EMT) by Beclin 1 knockdown via posttranscriptional upregulation of ZEB1 in thyroid cancer cells. Oncotarget 7: 70364-70377, 2016.

32. Gao HX, Yan L, Li C, Zhao LM and Liu W: miR-200c regulates crizotinib-resistant ALK-positive lung cancer cells by reversing epithelial-mesenchymal transition via targeting ZEB1. Mol Med Rep 14: 4135-4143, 2016.

33. Bussolati B, Grange C, Sapino A and Camussi G: Endothelial cell differentiation of human breast tumour stem/progenitor cells. J Cell Mol Med 13: 309-319, 2009.

34. Chroscinski D, Sampey D and Maherali N; Reproducibility Project; Cancer Biology: Registered report: Tumour vascularization via endothelial differentiation of glioblastoma stem-like cells. Elife 4, 2015. doi: 10.7554/eLife.04363.

35. Ricci-Vitiani L, Pallini R, Biffoni M, Todaro M, Invernici G, Cenci T, Maira G, Parati EA, Stassi G, Larocca LM and De Maria R: Tumour vascularization via endothelial differentiation of glioblastoma stem-like cells. Nature 468: 824-828, 2010.

36. Fan YL, Zheng M, Tang YL and Liang XH: A new perspective of vasculogenic mimicry: EMT and cancer stem cells (Review). Oncol Lett 6: 1174-1180, 2013.

37. Brabletz S and Brabletz T: The ZEB/miR-200 feedback loop-a motor of cellular plasticity in development and cancer? EMBO Rep 11: 670-677, 2010

38. Wellner U, Schubert J, Burk UC, Schmalhofer O, Zhu F, Sonntag A, Waldvogel B, Vannier C, Darling D, zur Hausen A, et al: The EMT-activator ZEB1 promotes tumorigenicity by repressing stemness-inhibiting microRNAs. Nat Cell Biol 11: 1487-1495, 2009.

39. Radisky DC: miR-200c at the nexus of epithelial-mesenchymal transition, resistance to apoptosis, and the breast cancer stem cell phenotype. Breast Cancer Res 13: 110, 2011. 